\title{
EL MODELO DE FICCIÓN POSMODERNISTA DE MCHALE EN LA NOVELA ESPAÑOLA ENTRE 1975 Y 1990
}

Partiendo del hecho de que en los estudios de literatura comparada contemporánea sobre el posmodernismo, la literatura española apenas figura ${ }^{1}$, el propósito del presente artículo consistirá en averiguar hasta qué punto este fenómeno conviene a la narrativa española contemporánea entre 1975 y 1990 . Y, de ser así, cuáles serían sus rasgos principales ${ }^{2}$. Las novelas serán analizadas en base del concepto del posmodernismo de Brian McHale, expuesto en Postmodernist Fiction (1987).

Según McHale, la principal característica del modernismo es la duda epistemológica. Es decir, las capitales preguntas y preocupaciones de los narradores se ubican en torno a procesos cognoscitivos como

[h] it?; How do they know it, and with what degree of certainty); How is knowledge transmitted from one knower to another, and with what degree of reliability?; How does the object of knowledge change as it passes from knower to knower?; What are the limits of the knowable? (McHale 1987: 9)

El posmodernismo, en cambio, se concentra principalmente en problemas y cuestiones relativos al ser; radicaliza y cuestiona las angustias epistemológicas, típicas del modernismo, de la siguiente manera:

"Which world is this? What is to be done in it? Which of my selves is to do it? Other typical postmodernist questions bear either on the ontology of the literary text itself or on the ontology of the world which it projects, for instances: What is a world?; What kinds of world are there, how are they constituted, and how do they differ?; What happens when different kinds

1 Resulta, pues, que en los estudios comparativos acerca del posmodernismo en la literatura, los únicos autores españoles que figuran esporádicamente son Juan Goytisolo y, como posmodernistas avant la lettre, Miguel de Unamuno y Miguel de Cervantes (!). En cambio, la literatura hispanohablante transatlántica (Borges, Fuentes, García Márquez, Vargas Llosa...) si suele calificarse de posmodernista en los estudios comparativos.

2 Se ha tenido en cuenta un corpus de novelas: La verdad sobre el caso Savolta (1975), Eduardo Mendoza; El río de la luna (1981), José Maria Guelbenzu; Gramática parda (1982), Juan García Hortelano; Un dia volveré (1982), Juan Marsé; Herrumbrosas lanzas (1983), Juan Benet; La orilla oscura (1985), José Maria Merino; Si te dicen que caí (1985), Juan Marsé; El testimonio de Yarfoz (1986), Rafael Sánchez Ferlosio; La ciudad de los prodigios (1986), Eduardo Mendoza; Diario de un hombre humillado (1987), Félix de Azúa; Juegos de la edad tardía (1989), Luis Landero; Todas las almas (1989), Javier Marias; Galindez (1990), Manuel Vázquez Montalbán; y El metro de platino iridiado (1990), Álvaro Pombo. Estas son catorce novelas extraidas de una encuesta realizada y publicada por el diario $E l$ Pais (9-10-1991) con motivo de la Frankfürter Büchmesse en Frankfurt (RFA), sobre "lo que hay que leer" de la literatura española posfranquista. Sin embargo, la lista de El País contiene quince novelas: Diario del artista en 1956 (1991), de Jaime Gil de Biedma -es decir, la 150 novela- se excluirá del presente artículo por tratarse primero, de una versión (póstuma) completa de Diario del artista seriamente enfermo (1974), y segundo, por ser un relato autobiografico y no una obra de ficción, como las restantes novelas. 
of world are placed in confrontation, or when boundaries between worlds are violated?; What is the mode of existence of a text, and what is the mode of existence of the world (or worlds) it projects; How is a projected world structured? And so on." (McHale 1987: 10)

Los problemas epistemológicos se convierten en problemas ontológicos, relativos al ser; dicho de otro modo, los problemas "of knowing" (íbidem: 10) se hacen "problems of modes of being" (ibidem: 10). La novela posmodernista nos ofrece una pluralidad de mundos (intercambiables): "an anarchic landscape of worlds in the plural" (ibidem: 37).

Para alcanzar esta 'anarquía', el posmodernismo utiliza varias estrategias (recursos) que acentúan y destacan las diferentes dudas ontológicas (en la novela), tanto a nivel del texto, las palabras, las frases... (words), como a nivel del contenido del texto ("the reconstructed world" (íbidem: 39)).

Cinco de las catorce novelas analizadas apenas tienen afinidades con el posmodernismo (de Brian McHale). Son principalmente de índole epistemológico. La verdad sobre el caso $\mathrm{Sa}$ volta (1975) persigue dos búsquedas epistemológicas, a saber, ¿quién mató a Enric Savolta, $\mathrm{y}$, la segunda, la reconstrucción de la vida de Javier Miranda, el protagonista, durante los años 1917-1927. Un día volveré (1982) se desarrolla en un mundo concreto y delimitado, la España franquista. Es una novela realista que nos ofrece un panorama realista de la España posbélica. Diario de un hombre humillado (1987) es una novela modernista. Su personaje -un hombre banal- es un clásico personaje modernista, cuyas principales características son la marginalidad, la imcomprensión y la soledad. El hombre banal trata de aprehender y estructurar la caótica y ambigua realidad. El distinguido catedrático anónimo de Todas las almas (1989) considera hablar, pensar y preguntar (actos relativos a la razón) como medios para comprender y alcanzar la "realidad". Y, por último, la familia pudiente madrileña de $E l$ metro de platino iridiado (1990) trata de encontrar la felicidad en un claro y delimitado mundo.

Luego hay cuatro novelas que ciertamente tienen varios rasgos posmodernistas, pero que no entran satisfactoriamente en la poética del posmodernismo según McHale. En última instancia, el acento de estas novelas recae en el aspecto epistemológico. Herrumbrosas lanzas (1983) linda con el posmodernismo por su escepticismo lingüistico pero no llega a desestabilizarse completamente la ontologia de la novela. Si bien pone en entredicho la relación entre la realidad y las palabras ${ }^{3}$, o aparecen distintas injerencias del narrador (recalcando su papel de creador) en el texto (reflejadas, por ejemplo, en las notas a pie de página, el plano desplegable del transcurso estratégico de la guerra...), éstas técnicas autorrefenciales no son lo suficientemente discursivas como para desestabilizar la ontología de la novela. Podríamos decir que son demasiado modestas.

El mundo -ficticio y fantástico- de El testimonio de Yarfoz (1986) es un solo mundo que ni se problematiza ni se cuestiona. A pesar de que no sepamos su ubicación, en la novela no se produce ningún planteamiento ontológico. Es más: el planteamiento básico de la novela gira en torno a una búsqueda epistemológica con preguntas de naturaleza fundamentalmente

3 La novela intenta hacernos ver que es imposible alcanzar y comprender la realidad mediante el lenguaje; véase, los constantes cambios de los nombres propios de los personajes (por ejemplo, Julián Fernández/ El Manchado/el capitán Andrés; (Benet 1983: 116)). 
congnoscitiva: El testimonio fue precisamente escrito a propósito de la verdad acerca de la vida de los principes Nébride y Yarfoz ${ }^{4}$.

En cuanto a su temática, Galíndez (1990), es una obra modernista (policíaca; intenta buscar la verdad sobre Jesús de Galíndez a través de ciertas investigaciones), pero en cuanto a la presentación, linda con el posmodernismo. Conciente de que la realidad es difícil de comprender y de abarcar, a la estudiante norteamericana Muriel Colbert le es imposible encontrar $l a$ verdad por estar siempre subordinada al lenguaje (léase en este caso: el texto escrito) ${ }^{5}$. Pero la novela Galíndez delimita los marcos de ambos planos -texto y realidad-sin sucumbir ante "...an anarchic landscape of worlds in the plural". (McHale: 37 )

Las novelas que responden, pues, a la poética del posmodernismo de Brian McHale son: El río de la luna (1981), de José María Guelbenzu; Gramática parda (1982), de Juan García Hortelano; La orilla oscura (1985), de José María Merino; La ciudad de los prodigios (1986), de Eduardo Mendoza; y Si te dicen que caí (1985), de Juan Marsé.

Por su estructura laberintica de mundos y submundos, El río de la luna logra confundir la supuesta realidad y el mundo onírico. El marco de referencia de la realidad de Gramática parda se esfuma por completo por el exhibicionismo lingüístico; la novela se concentra en el mundo de las palabras. Las infinitas 'cajas chinas' y niveles hipodiegéticos en La orilla oscu$r a$ son responsables de la desaparición ontológica de la novela. En La ciudad de los prodigios no sabemos qué pertenece a la Historia (con mayúscula) y qué a la ficción. En Si te dicen que caí, Juan Marsé nos presenta, a través de un escepticismo lingüístico y la multiplicación de voces y de relatos, una continua confusión entre 'aventis' (abreviatura de 'aventuras') y 'realidad' 6 .

Conforme a nuestros resultados, las estrategias de las novelas posmodernistas que plantean problemas ontológicos se dividen en dos grandes grupos. Obviamente, los dos grupos están estrechamente relacionados entre sí. Uno hace hincapié en estrategias que ponen en primer plano el medio lingüístico y nos revelan la estructura artificial de la novela. Son el exhibicionismo lingüístico y la heteroglosia. Otro, pone el énfasis en las estrategias que desdibujan las fronteras entre el mundo 'empírico' y el mundo ficticio. Y son, principalmente, la 'historia apócrifa', la 'transworld identity' y las 'muñecas rusas'.

Según McHale, la 'historia apócrifa' se propone contradecir de dos maneras la versión oficial de la Historia. O bien

it supplements the historical record, claiming to restore what has been lost or suppressed; or it displaces official history altogether. In the first of these cases, apocryphal history operates in the 'dark areas' of history, apparently in conformity to the norms of 'classic' historical fiction but in fact parodying them (McHale: 90 )

\footnotetext{
4 Sin embargo, entrando en el terreno de las ambigüedades, la obra se contradice, puesto que casi todo el testimonio trata y sabemos más acerca de otras cosas que del propio Nébride.

5 En busca de su verdad (véase Montalbán 1990: 24), Muriel sigue el itinerario geográfico (Pais Vasco, Madrid, Santo Domingo, Nueva York y Miami) que Galíndez recorrió hace treinta años. Y, simultáneamente, la obra nos confronta con el peculiar y extenso rastro de publicaciones que levantó el caso Galíndez.

6 Este hecho corresponde con la idea de que "en la inmediata posguerra nadie sabia lo que era realidad y lo que era ficción". (Sherzer en Marsé 1985: 42.
} 
En La ciudad de los prodigios, la parodia es un arma eficaz contra la versión oficial de la Historia ${ }^{7}$. Además, conforme la novela avanza, la división entre 'realidad' (Historia) y ficción se evapora hasta tal extremo que al final, el lector no sabe qué pertenece a la Historia y qué a la ficción.

Los constantes solapamientos de niveles narrativos -implicando cada vez un cambio de nivel ontológico- hacen que en La orilla oscura sea imposible distinguir entre ficción y 'reali$\mathrm{dad}^{8}$. Se pierde todo punto de referencia. Según uno de los personajes, todo es caos e incertidumbre:

...me encuentro ante un enigma cuyas condiciones son contradictorias: o yo, Anastasio Marzán Lobato soy el creador de un personaje denominado Pedro Palaz, de su efigie, de su biografia, de sus obras (...) o Pedro Palaz existe realmente y tiene una obra que yo no conozco... Si la primera alternativa es la verdadera, la segunda no puede siquiera plantearse. Si la alternativa verdadera es la segunda, ¿no me corresponderia más bien a mí la condición apócrifa? (Merino 1985: 222)

Como puede verse, en la novela "there is a 'fundamental vagueness' in the... description of its frontiers". (McHale 1987: 46). El lazo de unión entre una zona y otra es el sueño: "un ámbito difuso, espectral" (Merino 1985: 1985) ${ }^{9}$, que en la novela adquiere un valor simbólico, manifestándose cada vez en medio de la oscuridad (el sótano del museo, la selva...) ${ }^{10}$. El paso del sueño a la vida 'real' sucede tan sutilmente que tanto los propios personajes como el lector se enredan y se confunden en los distintos mundos.

En El río de la luna, la confusión ontológica se refleja entre otras cosas a través de sucesos que primero son presentados y después son negados por el entorno. Estos hechos "are proyected only to be abruptly negated" (McHale 1987: 102). No sabemos a ciencia cierta si estas ocurrencias son soñadas, narradas o empíricamente efectuadas ${ }^{11}$. Pero en el mundo de Guelbenzu, también se produce una especie de pluralización de mundos ${ }^{12}$. Leemos que al

...otro lado de la puerta se hallaba invertido como si fuera un espejo, el mismo local (...) si, uno puede recorrer cuantas veces quiera esta serie interminable de lugares y todos conducen a si mismo. En realidad no se sabe si son muchos o es siempre el mismo. Y, sin embargo, hay sutiles variantes de vez en cuando. (Guelbenzu (1981: 66)

7 Véase, por ejemplo, las características físicas de los barceloneses que influyeron en la historia (Mendoza 1987: 90)

8 Según McHale, los continuos desembragues narrativos "...serves as a tool for exploring issues of narrative authority, reliability and unrealiability..." (McHale 1987: 113)

9 El "ámbito difuso" oscila entre la zona que representa España (su “...casa paterna, rememorada con la luz de la niñez..." (Merino 1985: 42) y Latinoamérica (el remoto pasado).

10 Según Hassan (véase bibliografia), la desaparición del principio de autoridad (que hace que el mundo (en la novela) se descentralice o fragmentarice) nos conduce hacia un mundo caracterizado por, primero 'Indeterminacy', y segundo, 'Immanence'. La primera, relevante para nuestro trabajo, se refiere a los resultados (o consecuencias) de la desintegración y de la desaparición ontológica en la novela. Sus consecuencias inmediatas son la desintegración, la desmistificación y la autorreflexividad (Hassan 1993: 281).

11 Por ejemplo, el encuentro de José con el cura (Guelbenzu 1981: 98-99); o la 'sombra' del llamado hombre de la cicatriz a lo largo de toda la novela, que, en palabras de McHale, "flickers out of existence and then, flickers back into existence again" (McHale 1987: 104).

12 Especulando, estos mundos pueden representar la vida y la muerte: el mundo de 'arriba' y el mundo 'subterráneo', respectivamente. 
Concentrándonos en una estrategia responsable de desestabilizar la estructura ontológica a nivel del texto (las palabras, las frases, el estilo...), es menester hablar del llamado exhibicionismo lingüístico ${ }^{13}$. Desde la primera página, Gramática parda nos confronta con el protagonismo de la lengua ${ }^{14}$. La acción de los personajes disminuye (en muchos casos, es nula), mientras que la materia del texto, y el proceso de escribir y de cuestionar minuciosamente el lenguaje y la literatura, pasa al primer plano ${ }^{15}$. Las frases caracteristicas de la novela también nos llevan a un exhibicionismo estilístico y son "rambling, apparently interminable, shape shifting constructions..." (McHale 1987: 155). Por ejemplo, la siguiente:

...en ese entretanto, Paulette II, profesionalmente insaciable, ha telefoneado a George al despacho proponiéndole un almuerzo de enamorados, de modo que, cuando de seguido George recibe la llamada de Paulette, se inventa un almuerzo de negocios, invención que de nada le habria servido de nos ser porque, en ese preciso instante, Paulette recibe en el boudoir de manos de Venus Carolina Paula un mensaje, mediante el que se le propone un té incógnito para esa tarde, por lo que Paulette negocia con George que ella almorzará con el huésped a cambio de que èl cargue con el huésped a la hora del té de las cinco, puesto que ella a esa hora taurina tiene cita con la manicura, invención y pacto que, de no mediar un almuerzo con Paulette II, a Paulette de nada le habria servido, ya que George..., etcétera, etcétera... (García Hortelano 1982: 9495)

El exhibicionismo estilístico de este tipo de frases nos invita "to relieve them of their meaning and then defying us to put meaning back into them again. Only a sucker would take up the challenge: these sentences make suckers of their readers". (McHale 1987: 155). Pero, ¿qué consecuencias tiene el 'foregrounding' lingüístico en estas novelas? Según McHale, el lector entonces

...is constantly being distracted from the level of world to the level of words by means of a transparently pointless and empty formalism. The syntactical flow is disturbed, the projected world undermined, collapsing time and again, then reconstituting itself only to collapse once more; it flickers. (McHale 1987: 158)

En Gramática parda, este efecto de 'intermitencia' (flickers) se produce no solamente cuando los personajes recobran y pierden "con inusitada intermitencia los usos de su identidad" (García Hortelano 1982: 339), sino también cuando, al final de la novela, Teobaldo

13 Sabemos que en el posmodernismo, el lenguaje ha perdido su función referencial. Entonces, en palabras de Thiher, "all systems are games that seduce by virtue of their consistency as languages games" (Allen Thiher, Words in Reflection, Chicago: University of Chicago Press, 1984, p. 161). Por tanto, esta heterogeneidad nos conduce hacia una multiplicación de "justices" (véase Hans Bertens, The Idea of the Postmodern, London/New York: Routledge, 1995, p. 128 y ss.).

14 En cuanto a la estructura de la novela, los capitulos se dividen en 33 lecciones ('Las condiciones del sujeto', 'Dialectica de la concordancia'...); 7 ejercicios (de redacción, epistolares, de lectura...) un comentario de texto, un recreo y un apéndice (en donde se explica la necesidad de la gramática).

15 En la frontera entre Francia y España, un octogenario español se enreda en un absurdo diálogo bilingüe con un aduanero francés, Juan Jacobo. Además de distintos idiomas (que, por tanto, construyen distintos puntos de vista, mundos discursivos), la novela también contiene distintos registros (retórico, literario, soez...). 
García de García se desploma muerto en el tren, y, unas cuantas frases después resucita y muere otra vez, y otra vez y otra:

si moria otra vez, a Teobaldo sólo le quedaba confiar en una nueva resurreccion... (ibidem: 347 )

Pero, ¿resucita en el mismo mundo ('real', 'literario')? Y, ¿a qué mundo va cuando muere por segunda vez? Sea como sea, "[t]he reader becomes shizoid, his or her attention dived between the level of world and the level of words". (McHale 1987: 158)

Un rasgo común en prácticamente todas las novelas leídas es la confusión entre el mundo empírico y la ficción. Incluso las novelas cuyo acento no recae en problemas ontológicos, utilizan recursos que contribuyen a la posible confusión entre 'ficción' y 'realidad'.

Las estrategias más recurrentes de la novela española contemporánea entre 1975 y 1990 para poner en entredicho o plantear problemas ontológicos son: a nivel narrativo, la intertextualidad, la historia apócrifa, y las llamadas "muñecas rusas"; y, a nivel lingüístico, generalmente el exhibicionismo lingüístico. La desestabilización de la novela ocasiona dos efectos que forman una especie de marca común del presente corpus de novelas. Primero, la predominancia (y puesta en tela de juicio) del medio lingüistico, y segundo, la confusión entre 'realidad' y ficción. Como ha podido apreciarse, estos dos efectos se realizan en diferentes grados y con diferentes matices. La 'historia apócrifa' y el exhibicionismo lingüístico se reflejan al máximo en La ciudad de los prodigios y Gramática parda, respectivamente. Es menester apuntar que las dos características están estrechamente relacionadas entre sí. A veces, por ejemplo, el protagonismo del medio lingüístico tiene como consecuencia la desdibujación de los límites entre 'realidad' y ficción.

Pero, volviendo a la pregunta inicial de nuestro trabajo, si sólo cuatro de las catorce novelas de la narrativa española entre 1975 y 1990 son posmodernistas pur sang, debemos concluir que las técnicas y objetivos del posmodernismo, tal y como lo entiende y explica Brian McHale en Postmodernist Fiction, no convienen mucho a la novelística española de dicho período. Sin embargo, debemos subrayar que cada toma de postura es una limitación y una simplificación. Por una parte, el posmodernismo de McHale es una simplificación, una construcción discursiva, intersubjetiva para ejemplificar (y poder hablar sobre) cierta literatura en un cierto momento. Por otra parte, el presente corpus de novelas también es una reducción del sistema literario español entre 1975 y 1990 . Obviamente, la novela española contemporánea consta de más de catorce novelas. Hay que ser conscientes de que, en cuanto al posmodernismo, para obtener un panorama más completo, habria que incorporar, además de la generación del 68 y siguiente(s), también las generaciones del 36 (Cela, Torrente Ballester...) y la del 50 (los hermanos Goytisolo...). De cualquier modo, no deja de ser significativo el predominio de la narrativa "objetiva" en el corpus estudiado. 
Referencias bibliográficas

AZÚA, Félix de (1987). Diario de un hombre humillado. Barcelona: Anagrama

BENET, Juan (1983). Herrumbrosas lanzas. Madrid: Alfaguara

GARCÍA HORTELANO, Juan (1982). Gramática parda. Barcelona: Argos Vergara

GUELBENZU, José Maria (1981). El río de la luna. Madrid: Alianza

HASSAN, Ihab (1993), “Toward a Concept of Postmodernism", A Postmodern Reader (ed. J. Natoli \&

Hutcheon). Albany: University of New York Press, pp. 273- 286

LANDERO, Luis (1989). Juegos de la edad tardia. Barcelona: Tusquets

MARÍAS, Javier (1989). Todas las almas. Barcelona: Anagrama

MARSÉ, Juan (1982). Un día volveré. Barcelona: Seix Barral

MARSÉ, Juan (1985). Si te dicen que caí (ed. W.M. Sherzer). Madrid: Cátedra

McHALE, Brian (1987). Postmodernist Fiction. New York: Routlegde

MENDOZA, Eduardo (1975). La verdad sobre el caso Savolta. Barcelona: Seix Barral

MENDOZA, Eduardo (1986). La ciudad de los prodigios. barcelona: Seix Barral

MERINO, José María (1985). La orilla oscura. Madrid: Alfaguara

POMBO, Álvaro (1990), El metro de platino iridiado. Madrid: Anagrama

SÁNCHEZ FERLOSIO, Rafael (1986). El testimonio de Yarfoz. Madrid: Alianza

VÁZQUEZ MONTALBÁN, Manuel (1994). Galindez. Barcelona: Planeta

MCHALOV MODEL POSMODERNISTIČNE FIKCIJE V ŠPANSKEM ROMANU 1975-1990

V študijah primerjalne književnosti sodobna španska literatura zvečine ne nastopa kot postmodernistična. Članek poskuša na temelju tehtnega korpusa štirinajstih španskih romanov, objavljenih v obdobju med 1975 in 1990, dognati, v kakšnem obsegu je mogoče govoriti o sodobni postmodernistični španski fikciji. Za postmodernistični model nam rabijo zlasti zamisli Briana McHala in njegovo pojmovanje epistemologije (modernizem) in ontologije (postmodernizem) po knjigi Postmodernist Fiction (1987). Tu rabimo raznovrstne tehnike in strategije, ki jih postavlja Brian McHale, da bi ugotovili morebitno navzočnost in vpliv t. i. postmodernizma na sodobno špansko pripovedništvo med 1975 in 1990. Zazdaj moramo, če si vnaprej ogledamo sklepe te obdelave, ugotoviti, da tehnike in izrazi postmodernizma na način, kot jih razume in pojasnjuje Brian McHale, ne ustrezajo španskemu romanopisju omenjenega obdobja. 